\title{
COLETA DO FLUIDO GENGIVAL EM PACIENTES ORTODÔNTICOS
}

Nancy Kudsi de CARVALHO; Stephanie DRUMMOND; Cristiane CANAVARRO; Jonas Capelli JÚNIOR.

O movimento dentário ortodôntico é inicialmente caracterizado por uma resposta inflamatória aguda no periodonto, onde ocorre vasodilatação e migração de leucócitos para fora dos capilares. $O$ volume do fluido gengival $(F G)$ dos dentes em movimento aumenta de forma significante sendo evidenciado através da coleta e posterior análise do FG. A técnica mais utilizada é a coleta com tiras de papel absorvente (Periopaper®). $\mathrm{O}$ objetivo deste trabalho é apresentar um método de coleta do fluido gengival de dentes submetidos à movimentação ortodôntica com as tiras de papel absorvente, e isolamento da área a ser coletada com roletes de algodão, secando a mesma com jatos de ar. A tira é introduzida no sulco até encontrar resistência e permanece nesta posição por trinta segundos. Em seguida a tira é colocada no Periotron, que quantifica em microlitros o volume do FG. A tira de papel absorvente pode ser utilizada no estudo do movimento dentário pela rapidez da coleta, fácil manejo, menor traumatismo, poder ser usada em sítios individuais e possui duas finalidades básicas: quantificar o volume e analisar os metabólitos envolvidos nas reações inflamatórias causadas pela movimentação dentária. Mostra-se uma interessante alternativa na compreensão dos fenômenos envolvidos. 